\title{
Exocrine and Endocrine Pancreatic Cancer cM0 TNM Finding v7
}

National Cancer Institute

\section{Source}

National Cancer Institute. Exocrine and Endocrine Pancreatic Cancer cMO TNM Finding v7. NCl Thesaurus. Code C90303.

Exocrine or endocrine pancreatic cancer without evidence of distant metastasis. (from AJCC 7th Ed.) 